\title{
PEGylated $\beta-\mathrm{NaGdF}_{4}: \mathrm{Tb} @ \mathrm{CaF}_{2}$ Core/Shell
}

\section{Nanophosphors for Enhanced Radioluminescence and \\ Folate Receptor Targeting}

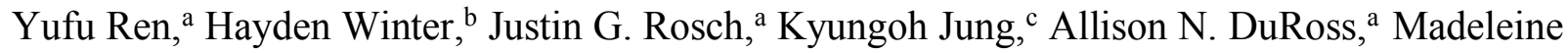

R. Landry, ${ }^{a}$ Guillem Pratx ${ }^{\mathrm{c}}$ and Conroy Sun*,a,d

a Department of Pharmaceutical Sciences, College of Pharmacy, Oregon State University, 2730

SW Moody Ave, Portland, OR 97201, USA

${ }^{b}$ Department of Chemistry, College of Liberal Arts \& Sciences, Portland State University, 1719 SW 10th Ave, Portland, OR 97201, USA

${ }^{c}$ Department of Radiation Oncology, School of Medicine, Stanford University, 300 Pasteur Drive, Stanford, CA 94305, USA

d Department of Radiation Medicine, School of Medicine, Oregon Health \& Science University, 3181 S.W. Sam Jackson Park Road, Portland, OR 97239, USA

${ }^{*}$ Corresponding authors.

E-mail addresses: sunc@,ohsu.edu (C. Sun). 
(a)

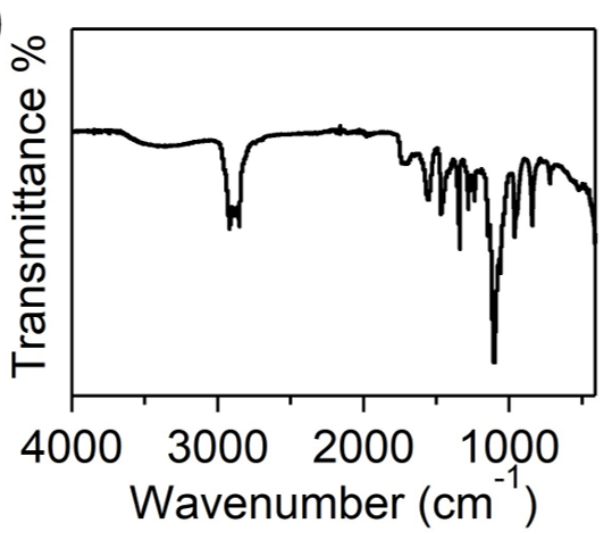

(b)

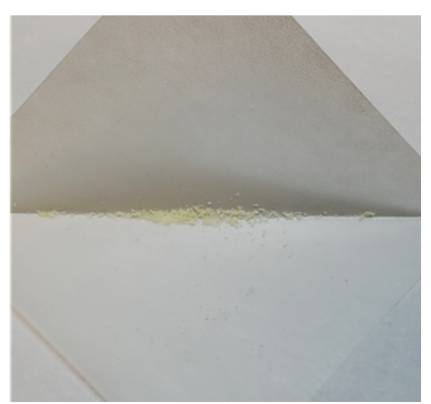

Figure S1. (a) FTIR spectra of the $\beta-\mathrm{NaGdF}_{4}: \mathrm{Tb} @ \mathrm{CaF}_{2} @ D S P E-P E G-F A$ nanoparticles and (b) photograph of the as-prepared $\beta-\mathrm{NaGdF}_{4}: \mathrm{Tb} @ \mathrm{CaF}_{2} @ \mathrm{DSPE}-\mathrm{PEG}-\mathrm{FA}$ nanoparticles after freeze drying.
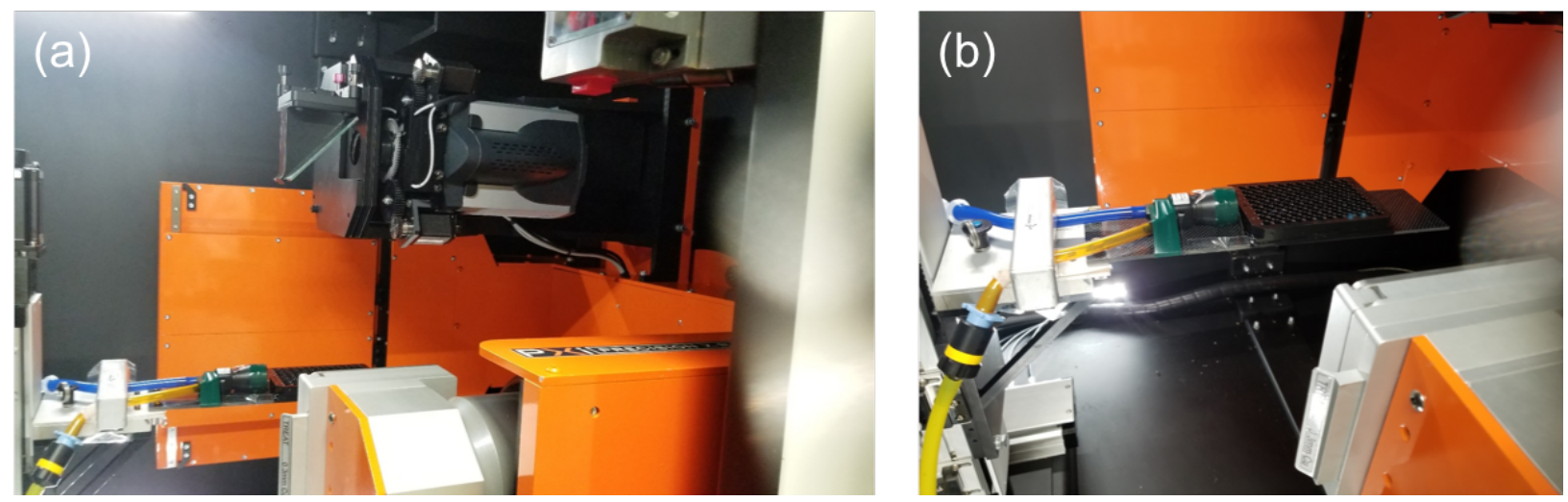

Figure S2. (a) photograph of X-RAD SmART, Precision X-Ray system for X-ray excited luminescence imaging and (b) photograph of 96-well plate sample position during imaging. 


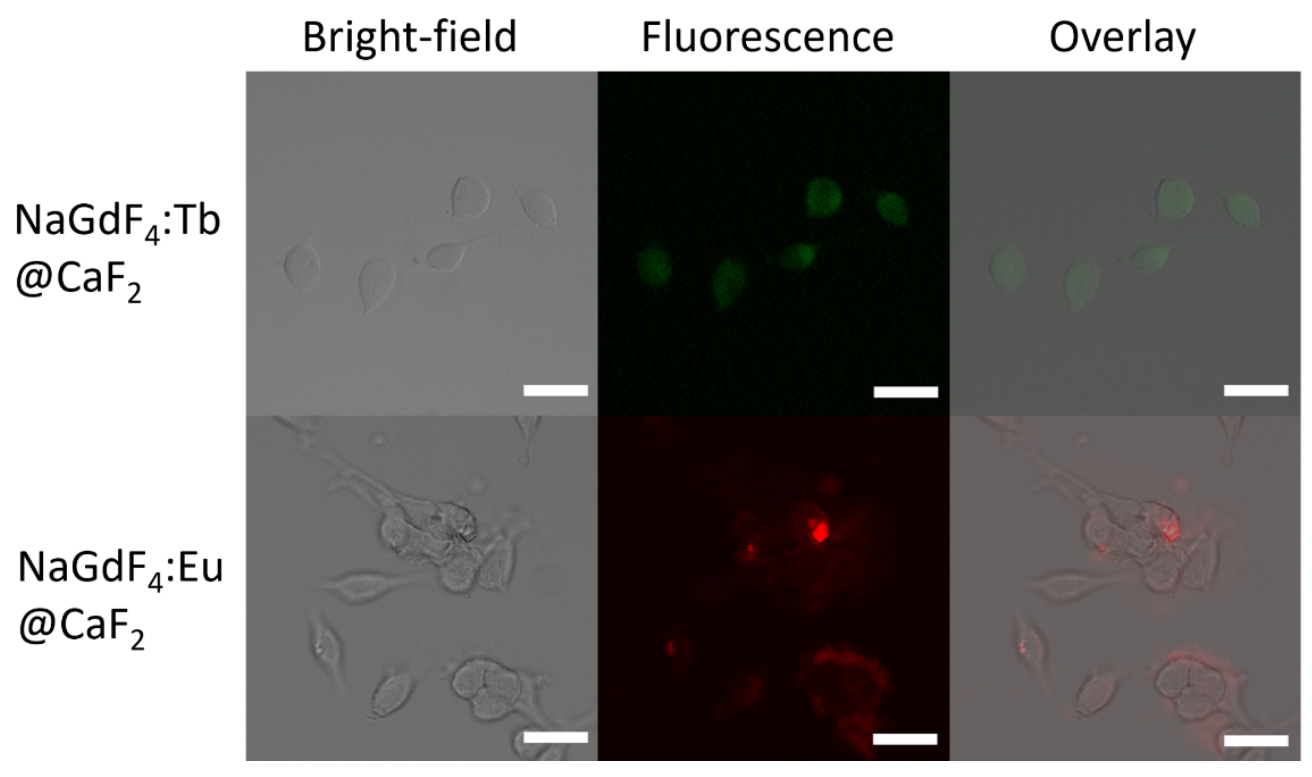

Figure S3. Confocal images of the CT26 cells incubated with $\beta-\mathrm{NaGdF}_{4}: \mathrm{Tb}_{\mathrm{C}} @ \mathrm{CaF}_{2} @ \mathrm{DSPE}-\mathrm{PEG}-$ FA and $\beta-\mathrm{NaGdF}_{4}: \mathrm{Eu} @ \mathrm{CaF}_{2} @$ DSPE-PEG-FA nanoparticles. Green and red fluorescence represent the emission from $\mathrm{Tb}^{3+}$ and $\mathrm{Eu}^{3+}$ of the nanophosphors respectively. 